\section{Delegation of section 5(2) Mental Health Act 1983}

Sir: Section 5(2) of the Mental Health Act (MHA) 1983 is the first piece of psychiatric law the junior doctor will come across, yet there remains great confusion about the delegation of its powers. This section, which allows detention for up to 72 hours on psychiatric grounds, may be placed on any in-patient by his or her consultant. If absent, the consultant may nominate one doctor from the same hospital to act as a deputy. Jones (1991) suggests that this nomination "should be put in writing and conveyed to all relevant staff"; it is unclear whether or not a nomination by telephone is legal. Since emergency detention in general hospital practice is uncommon, non-psychiatrist consultants rarely post details of their deputy for purposes of the MHA. Some hospitals make whichever consultant is on call for a particular speciality the nominated deputy for all consultants in that speciality. What is clear is that the nominee may not further delegate to a junior, because of the legal principle delegatus non potest delegare.

The Mental Health Act Code of Practice (HMSO, 1990), which is not legally binding but does lay out standards of practice, suggests that only consultant psychiatrists should delegate, and they should also satisfy themselves that the nominee is sufficiently trained in psychiatry. If this were rigidly followed, then outside psychiatry only the consultant in charge of a case could use a section $5(2)$ no matter when. There is no change in this guidance in the revised Code of Practice, which came into force in November 1993.

In practice there can be great confusion with the on-call junior psychiatrist giving advice to a medical or surgical house officer who may have been hastily made the on-call consultant's deputy by telephone. An alternative is for every general consultant to nominate for purposes of the MHA whichever junior psychiatrist is on call for liaison in their hospital. In most psychiatric hospitals this is done by a brief statement on the on-call rota. This would satisfy legal requirements and avoid poor practice. It should not greatly increase workload on the psychiatrist, who is usually already involved if an in-patient requires detention.

HMSO (1990) Code of Practice Mental Health 1983 London: HMSO.

JONES, R. (1991) Mental Health Act Manual. 3rd ed. London: Sweet \& Maxwell.

J. H. M. CRICHTON, Institute of Criminology, 7 West Rd, Cambridge, CB3 9DT; and $\mathrm{K}$. TOWNSEND, West Suffolk Hospitals Trust, Hardwick Lane, Bury St Edmunds, IP33 2QZ

\section{Teaching seruality within medical education}

Sir: It was heartening to read about the inaugural meeting of the Association of Teachers of Sexuality within Medical Education (ATSME) (Psychiatric Bulletin, 17, 677-678). I was reminded of my volunteer work in the Singapore Planned Parenthood Association (SPPA), a founder member of the International Planned Parenthood Federation (IPPF) based in London.

Interestingly, I began this volunteer work as a medical student in Singapore. There was little sexuality teaching in medical school. Indeed, it was the SPPA which conducted an annual sexuality seminar for final-year students, but here the emphasis was on sexual dysfunctions and contraception, with nothing about the 'soft' issues, i.e. value systems and interpersonal relationships. Sadly, these seminars ended after three years because of constraints in the medical school time-table.

I found myself, a medical student then, learning all about sexuality through my volunteer work, and simultaneously becoming equipped to teach sexuality to teenagers. (Formal sex education was, and still is largely non-existent in Singapore schools).

The experience was valuable in that it made me realise how ill-equipped doctors can be in dealing with sexuality issues in their patients, let alone in themselves. In acquiring sexuality education I learnt more about myself in the process, and understood better the different attitudes and value systems of others. I also found myself taking better psychosexual histories in a sensitive and non-judgemental manner.

I agree with the ATSME about the need to establish a core curriculum. I found this to be a crucial first step when lobbying the education .policymakers in Singapore. I would like to offer some suggestions.

(a) Meet with medical school curriculum committees to discuss the role of sexuality education, and assess what they expect and what goals they might have for such education.

(b) Involve medical students in sexuality teaching projects for teenagers, in collaboration with local family planning services or youth groups. The experience gained would be invaluable, while contributing a service to the community.

(c) Draw on resources in the excellent library at the IPPF. Programme designs and evaluation methods are well described, and would facilitate research.

JEYABALA BALAKRISHNA, Atkinson Morley's Hospital, London SW20 ONE 